\title{
Synthesis and Characterization of Block Copolymers: Poly(ethylene oxide- $b$-methacrylonitrile) and Poly(ethylene oxide-b-acrylonitrile)
}

\author{
Toshimitsu Suzuki, Yoshimasa MuraKami, \\ and Yoshinobu TAKEGAMI \\ Department of Hydrocarbon Chemistry, Faculty of Engineering, \\ Kyoto University, Kyoto 606, Japan.
}

(Received July 10, 1981)

\begin{abstract}
Anionic polymerization of methacrylonitrile was initiated with the disodium salt of poly(ethylene oxide) (PEO) in tetrahydrofuran (THF) at various temperatures in both the presence and the absence of a crown ether or cryptate. In the polymerization at $30^{\circ} \mathrm{C}$ in the presence of a crown ether, methanol soluble and insoluble block copolymers of PEO and polymethacrylonitrile were obtained and the composition of the copolymer could be controlled by the feed mole ratio of monomer to initiator. Anionic polymerization of acrylonitrile was also intiated with the disodium salt of PEO in THF at various temperatures. A very small amount of PEO was incorporated into the resulting block copolymer. A branched structure was formed in the polyacrylonitrile (PAN) part of the copolymer through a metalation reaction of PAN. The amount of branched structure decreased with a decrease in the polymerization temperature and was negligible in the copolymer prepared at $-78^{\circ} \mathrm{C}$.

KEY WORDS Anionic Polymerization / Methacrylonitrile / Acrylonitrile / Poly(ethylene oxide) / Sodium Alkoxide / Triblock Copolymer / Crown Ether / Cryptate / Nuclear Magnetic Resonance / Branched Structure /
\end{abstract}

Block copolymers containing physically and chemically different segments in one macromolecular chain can be expected to show interesting physical properties as compared with polymer blends or random copolymers. They can be used as thermoplastic elastomers, surfactants, or biochemical membranes. A large number of block copolymers have been synthesized and some are currently available on the market. ${ }^{1}$

In previous papers, we reported the synthesis of a triblock copolymer of poly(ethylene oxide) (PEO) and poly(methyl methacrylate) (PMMA). ${ }^{2-5}$ The anionic polymerization of methyl methacrylate (MMA) initiated with the disodium salt of PEO was accompanied by a transesterification reaction and a PEO grafted block copolymer was obtained. ${ }^{2,4}$ Since sodium methoxide initiates the anionic polymerization of acrylonitrile (AN) or methacrylonitrile (MAN) ${ }^{6-8}$ the polymerization of $\mathrm{AN}$ or MAN initiated with the disodium salt of PEO having a cation-binding property like a crown ether ${ }^{4,9,10}$ seems to proceed easily. Since polyacrylonitrile (PAN) and polymethacrylonitrile (PMAN) are chemically stable polymers, a block copolymer of PEO and either PAN or PMAN may have many useful applications. The polymerization of $\mathrm{AN}$ with the disodium salt of PEO has already reported by Furukawa et al. ${ }^{11}$ and Galin. ${ }^{12}$ Furukawa et al. confirmed the formation of a copolymer of PEO and PAN, and Galin suggested the possibility of side reactions. However, the details of this polymerization and the characterization of the resulting copolymer have not been elucidated. The block copolymer of PEO and PMAN has not yet been synthesized.

We have studied the anionic polymerization of MAN and AN initiated with the disodium salt of PEO in both the presence and absence of a crown ether or cryptate. The structure of the resulting block copolymers and the effect of the addition of either a crown ether or a cryptate are discussed. 


\section{EXPERIMENTAL}

\section{Materials}

Tetrahydrofuran (THF) and benzene were distilled twice over $\mathrm{LiAlH}_{4}$ under a nitrogen atmosphere and stored over molecular sieves 4A. MAN and AN (Nakarai Chemicals, Ltd.) were purified by the usual methods and distilled over calcium hydride under reduced pressure and stored over molecular sieves 4A. Sodium naphthalene was prepared in THF with naphthalene and metallic sodium. A crown ether, dicyclohexyl-18-crown-6 (Nakarai Chemicals, Ltd.), and a cryptate, kryptofix[222] $[4,7,13,16,21,24$-hexaoxa-1,10-diazabicyclo $(8,7,8)$ hexacosane; Merck], were freeze-dried from the benzene solutions and stored as benzene solutions. Commercial PEO \#1000 $\left(M_{n}=980, M_{w} / M_{n}=1.06\right)$, PEO \#4000 $\left(M_{n}=3600, M_{w} / M_{n}=1.03\right)$ and PEO $\# 6000\left(M_{n}=4600, M_{w} / M_{n}=1.06\right)$ were freeze-dried from the benzene solutions before use.

\section{Polymerization and Recovery of Copolymer}

The polymerization of AN and MAN were carried out in THF. The polymerization apparatus and procedure were the same as described previously. ${ }^{4}$ The reaction mixture was concentrated to one-third of its volume and poured into a large amount of methanol. A methanol-insoluble fraction was recovered as a product. In the polymerization of MAN, a methanol-soluble fraction was concentrated and washed with benzene, and the benzeneinsoluble polymer was also recovered as a product.

\section{Characterization of the Copolymers}

${ }^{13} \mathrm{C}$ NMR spectra were recorded in the Pulse Fourier Transform mode at $25.0 \mathrm{MHz}$ on a JEOLFX100 and ${ }^{1} \mathrm{H}$ NMR spectra were obtained on a Varian HR-220 at $220 \mathrm{MHz} .{ }^{1} \mathrm{H}$ and ${ }^{13} \mathrm{C}$ NMR spectra of the copolymers of PEO and PMAN in trifluoroacetic acid solutions were recorded at $60^{\circ} \mathrm{C}$ and the assignment of the PMAN portion in the copolymers was carried out according to the procedure in previous works. ${ }^{13,14}{ }^{1} \mathrm{H}$ and ${ }^{13} \mathrm{C}$ NMR spectra of the copolymers of PEO and PAN in dimethyl- $d_{6}$ sulfoxide solutions were recorded at ambient temperature. and the assignment of the PAN portion in the copolymers was carried out by the same procedure employed in previous works. ${ }^{15,16}$ Gel permeation chromatograms (GPC) were recorded on a Waters ALC/GPC 244, equipped with four $\mu$-styragel columns $\left(10^{5}+10^{4}+10^{3}+500 \AA\right)$ with THF as the eluent $\left(1.5 \mathrm{ml} \mathrm{min}^{-1}, 25^{\circ} \mathrm{C}\right)$. The weight-average molecular weight $\left(M_{w}\right)$ and the number-average molecular weight $\left(M_{n}\right)$ of the polymers were estimated from their GPC traces. Standard polystyrenes were used for calibration of polymer molecular-weight. Infrared spectra were recorded on a Hitachi model 215.

\section{RESULTS AND DISCUSSION}

\section{Polymerization of MAN}

The results of polymerization of MAN are summarized in Table I. Polymers No. 2-7 were not completely soluble in THF while polymers No. 8 and 9 were soluble. Since PEO is soluble and PMAN insoluble in methanol, the reaction mixture was poured into methanol to recover the block copolymer. As expected, the copolymer was recovered as a methanol-insoluble solid and showed absorptions of nitrile and ether groups in the infrared spectrum $\left(v_{\mathrm{C} \equiv \mathrm{N}}\right.$ at $2240 \mathrm{~cm}^{-1}$ and $v_{\mathrm{C}-\mathrm{O}-\mathrm{C}}$ at $1100 \mathrm{~cm}^{-1}$ ). In certain cases, appreciable amounts of solid polymers were recovered from methanolsoluble fractions. The infrared spectra of the methanol-soluble polymers showed a peak due to nitrile stretching vibration at $2240 \mathrm{~cm}^{-1}$, indicating that a part of the block copolymer was soluble in methanol. To remove the unreacted initiator fragment, the methanol-soluble polymers recovered by the evaporation of methanol were washed repeatedly with benzene.

In Figure 1 are shown the ${ }^{1} \mathrm{H}$ NMR spectra of the methanol-insoluble and -soluble fractions of polymer No. 5 prepared at $30^{\circ} \mathrm{C}$ in the presence of the crown ether. In both spectra, methylene proton resonance of PEO (3.8 $\delta$ ), $\alpha$-methyl proton $(1.9 \delta)$, and meso $(2.1 \delta, 2.6 \delta)$ and racemic $(2.4 \delta)$ dyads of $\beta$-methylene proton resonances of PMAN could be observed and no unidentifiable absorption was detected. ${ }^{13}$ In the ${ }^{13} \mathrm{C}$ NMR spectra of the copolymers, the methylene carbon resonance of PEO (72.2 ppm) and $\alpha$-methyl carbon resonance (27 $\mathrm{ppm})$, quaternary carbon resonance (35.7 ppm), $\beta$ methylene carbon resonance (55 ppm) and nitrile carbon resonance $(125 \mathrm{ppm})$ of PMAN were observed and no unidentifiable absorption was detected. ${ }^{14}$

Figure 2 shows the GPC traces of methanol- 
Synthesis of Block Copolymers

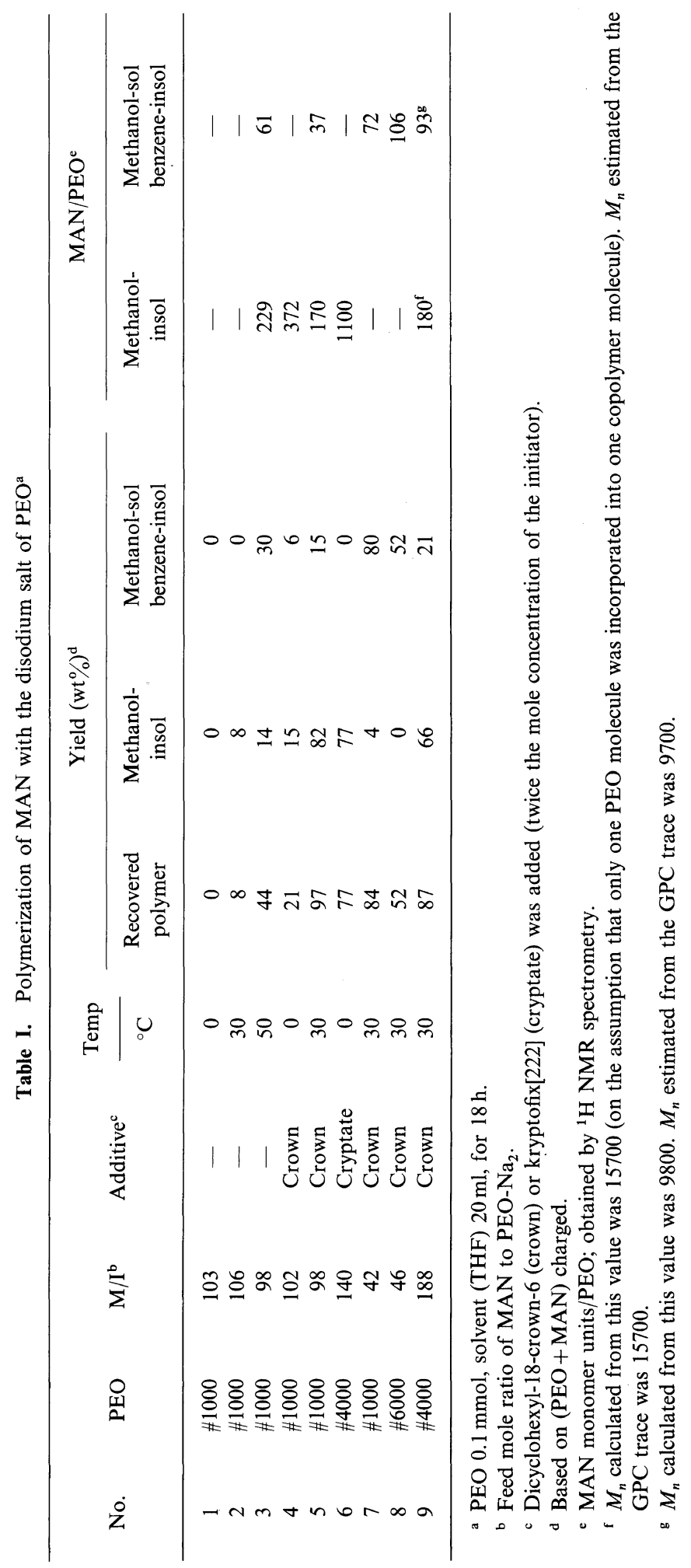




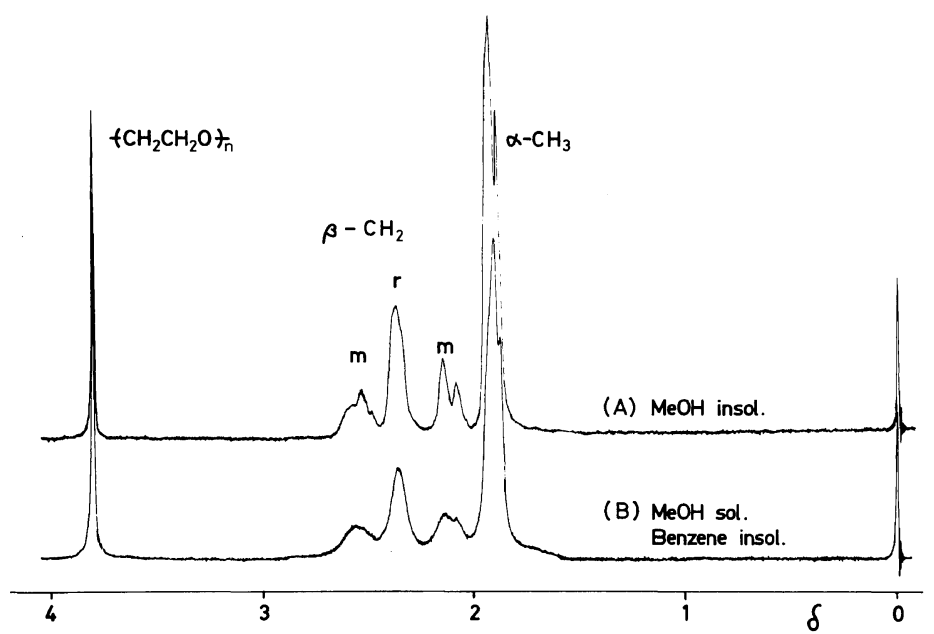

Figure 1. $220 \mathrm{MHz}{ }^{1} \mathrm{H}$ NMR spectra of PEO-b-PMAN No. 5 prepared at $30^{\circ} \mathrm{C}$ in the presence of the crown ether: (A) methanol-insoluble fraction; (B) methanol-soluble and benzene-insoluble fraction.

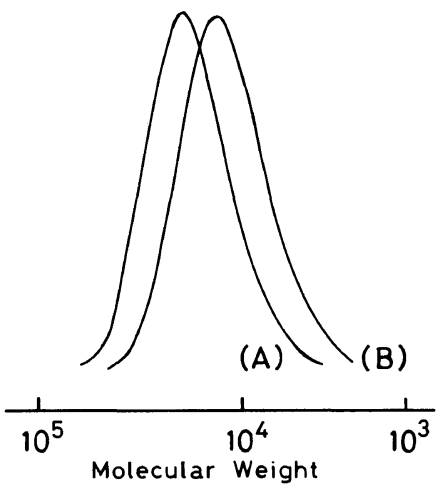

Figure 2. Gel permeation chromatograms of PEO- $b$ PMAN No. 9 prepared at $30^{\circ} \mathrm{C}$ in the presence of the crown ether: (A) methanol-insoluble fraction; (B) methanol-soluble and benzene-insoluble fraction.

insoluble and -soluble fractions of polymer No. 9. The molecular weight distributions of each fraction are fairly narrow and unimodal: $M_{w} / M_{n}=1.31$ (insoluble), 1.40 (soluble). The $M_{n}$ of the methanolinsoluble and -soluble fractions were 16000 and 9800 , respectively. These values agree very closely with the $M_{n}$ calculated from ${ }^{1} \mathrm{H}$ NMR spectra, as can be seen from Table I. Therefore, the polymerization proceeded uniformly without any side reactions.

The stereosequence distributions of the PMAN part in the copolymers were estimated from the splitting of $\alpha$-methyl carbon resonances. The PMAN part in the copolymers was essentially atactic. The fraction of the $r r$ triads of the PMAN part in the copolymer prepared in the presence of the cryptate was larger than that of the crown ether: $m m=0.25, m r+r m=0.48$ and $r r=0.27$ in No. 6 (cryptate); $m m=0.25, m r+r m=0.57$ and $r r=0.18$ in No. 4 (crown).

\section{The Effect of Polymerization Temperature and Additives}

In the absence of the additives (No. 1-3 in Table I), the yield of the copolymer increased with an increase in the polymerization temperature (from $0 \%$ at $0^{\circ} \mathrm{C}$ to $44 \%$ at $50^{\circ} \mathrm{C}$ ). In the presence of the crown ether, similar results were observed (from $21 \%$ at $0^{\circ} \mathrm{C}$ to $97 \%$ at $30^{\circ} \mathrm{C}$ ). Thus, the increase in polymerization temperature markedly brings about an increase in the yield of copolymer.

At $0^{\circ} \mathrm{C}$, no polymerization occurred at all in the absence of the additives. However, in the presence of either the crown ether or the cryptate, a considerable amount of the copolymer was obtained even at $0^{\circ} \mathrm{C}(21 \%$ and $77 \%)$. At $30^{\circ} \mathrm{C}$, the yield of copolymer reached $97 \%$ in the presence of the crown ether, while only an $8 \%$ yield was obtained in the absence of this additive. The addition of either the crown ether or the cryptate resulted in a great increase in the copolymer yield. Thus, the nucleo- 
philicity of the alkoxy anions of PEO is enhanced by the crown ether or the cryptate in the polymerization of MAN. This behavior differs from that of the polymerization of MMA reported previously, i.e., a $91 \%$ yield was obtained at $30^{\circ} \mathrm{C}$ even in the absence of the crown ether. ${ }^{4}$

The reactivity of MAN in the anionic polymerization initiated with $n$-butyllithium in THF is considered to be lower than that of MMA or AN. ${ }^{17}$ Therefore, the activation of propagating anions by the additives seems to be an important factor for increasing the polymer yield. This is also supported by the results of ${ }^{13} \mathrm{C}$ NMR spectrometry, i.e., the fraction of $r r$ triads of PMAN increased by the addition of the cryptate; the increase in the fraction of $r r$ triads suggests the formation of an agentseparated ion pair at a propagating chain end. ${ }^{4}$

The ratios of the MAN monomer units to one PEO chain in the copolymer (MAN/PEO) were obtained by ${ }^{1} \mathrm{H}$ NMR spectra and are listed in Table I. The ratios of MAN/PEO of copolymers prepared at $30^{\circ} \mathrm{C}$ in the presence of the crown ether are not significantly different from the feed mole ratios of monomer to initiator $(\mathrm{M} / \mathrm{I})$. However, the value of MAN/PEO of copolymer No. 6 prepared in the presence of the cryptate is much higher than the $\mathrm{M} / \mathrm{I}$ ratio $(\mathrm{MAN} / \mathrm{PEO}=1100$ and $\mathrm{M} / \mathrm{I}=140)$. The cryptate enhances the propagation reaction greatly as compared with the initiation reaction. Therefore, the addition of the cryptate is undesirable for the preparation of the block copolymer, even though it enhances the reaction rate.

In Figure 3 are shown the yields of methanolinsoluble copolymer as a function of polymerization time in the polymerization of MAN at $30^{\circ} \mathrm{C}$ in the presence of the crown ether. Since high yields were obtained over short reaction periods, the crown ether was thus proved to accelerate the propagation reaction. If it is assumed that the crown ether activates the propagation reaction much more than the initiation reaction, the value of MAN/PEO of resulting copolymer should then be fairly greater than that of $\mathrm{M} / \mathrm{I}$. In practice, however, these two values do not differ so much from each other, e.g., $\mathrm{MAN} / \mathrm{PEO}=72$ (observed) for $\mathrm{M} / \mathrm{I}=42$ (expected) in No. 7 and $\mathrm{MAN} / \mathrm{PEO}=180$ (observed) for $M / I=188$ (expected) in No. 9. Furthermore, the correlation of these two values is good, e.g., when the value of $\mathrm{M} / \mathrm{I}$ varies from 98 to 42 , the value of MAN/PEO varies from 170 to 72 (No. 5 and 7).

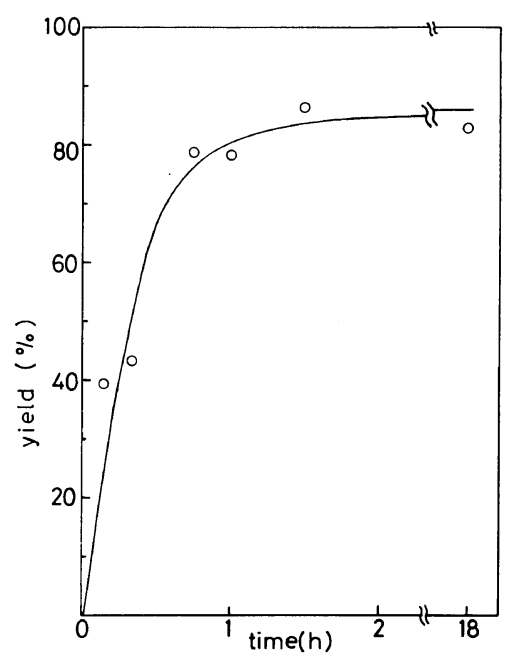

Figure 3. The yields of methanol-insoluble PEO- $b$ PMAN as a function of polymerization time: at $30^{\circ} \mathrm{C}$ in the presence of the crown ether; $M / I=100$.

These results indicate that the crown ether accelerates the propagation reaction moderately as does also the initiation reaction and that the polymerization proceeds uniformly at $30^{\circ} \mathrm{C}$ by the addition of the crown ether. Since the reactivities of alkoxy anions of both chain ends of PEO are considered to be of the same order, the possibility of exclusive formation of a diblock copolymer such as PMANPEO-OH is very small. From the discussion described above and the results described in the previous section, it is reasonable to consider that the polymerization at $30^{\circ} \mathrm{C}$ in the presence of the crown ether gives mainly the linear block copolymer of PEO-PMAN. Above all, under the experimental conditions in runs 5,7 , and 9, considerable amounts of the triblock copolymer of PEO and PMAN (PMAN-PEO-PMAN) can be obtained.

\section{Solubilities of the Block Copolymers}

Since PEO is soluble and PMAN insoluble in methanol, the methanol-insoluble and -soluble fractions of the copolymers may contain high and low molecular weight portions of PMAN, respectively. Therefore, the solubilities of the block copolymers in methanol will change with the values of $\mathrm{M} / \mathrm{I}$ when the molecular weights of PEO blocks are the same. In practice, on comparing No. 5 with No. 7 , when the value of M/I changes from 98 to 42, the yields of methanol-insoluble and -soluble copoly- 
mers change from $82 \%$ and $15 \%$ to $4 \%$ and $80 \%$, respectively. When the molecular weight of PEO block increases from 980 to 4600 , on comparing No. 5 with No. 8, the amount of methanol-soluble copolymer increases even if there is an increase in the number of MAN monomer units attached to the PEO block.

Thus, the block copolymers of PEO and PMAN having different solution properties can be obtained easily by varying the ratio of $\mathrm{M} / \mathrm{I}$ and/or the molecular weight of PEO.

\section{Polymerization of $A N$}

The results of the polymerization of $\mathrm{AN}$ are summarized in Table II. The reaction mixture was poured into a large amount of methanol. The methanol-soluble fraction was evaporated to dryness to give a small amount of solid which showed a strong absorption due to ether group $\left(v_{\mathrm{C}-\mathrm{O}-\mathrm{C}}\right.$ at $\left.1100 \mathrm{~cm}^{-1}\right)$ and a weak absorption due to nitrile group $\left(v_{\mathrm{C} \equiv \mathrm{N}}\right.$ at $\left.2240 \mathrm{~cm}^{-1}\right)$. Thus, the methanolsoluble fraction contained unreacted PEO as well as a small amount of copolymer. Since a portion of the soluble fraction was very small, a methanolinsoluble fraction was analyzed as a copolymer. It should be noted that the possibility of contamination with PAN homopolymer in methanolinsoluble fraction cannot be excluded.

As can be seen from Table II, the product yields are fairly low compared with the results in the

Table II. Polymerization of $\mathrm{AN}$ with the disodium salt of PEO \#4000 a

\begin{tabular}{|c|c|c|c|c|}
\hline \multirow{2}{*}{ No. } & \multirow{2}{*}{$\mathrm{M} / \mathrm{I}^{\mathrm{b}}$} & \multirow{2}{*}{$\frac{\text { Temp }}{{ }^{\circ} \mathrm{C}}$} & \multirow{2}{*}{$\begin{array}{c}\text { Yield }^{\mathrm{c}} \\
\mathrm{wt} \%\end{array}$} & \multirow{2}{*}{$\mathrm{AN} / \mathrm{PEO}^{\mathrm{d}}$} \\
\hline & & & & \\
\hline 10 & 228 & 30 & 39 & 700 \\
\hline $11^{\mathrm{e}}$ & 226 & 30 & 46 & - \\
\hline 12 & 20 & 0 & 20 & 770 \\
\hline 13 & 198 & 0 & 61 & 670 \\
\hline 14 & 194 & -30 & 37 & 490 \\
\hline 15 & 214 & -78 & 24 & 1570 \\
\hline
\end{tabular}

a PEO $0.1 \mathrm{mmol}$, solvent (THF) $20 \mathrm{ml}$, for $18 \mathrm{~h}$.

b Feed mole ratio of MAN to PEO-Na $a_{2}$.

c Yield of methanol-insoluble fraction based on $(\mathrm{PEO}+\mathrm{AN})$ charged.

d AN monomer units/PEO; obtained by ${ }^{1} \mathrm{H}$ NMR spectrometry.

e Dicyclohexyl-18-crown-6 was added (twice the mole concentration of the initiator). polymerization of MMA. ${ }^{4}$ This may be due partly to the inhomogeneity of this polymerization system: (a) polymer precipitates gradually during polymerization in THF; (b) the initiator is not sufficiently soluble in THF below $-30^{\circ} \mathrm{C}$. Very few effects of the addition of the crown ether and polymerization temperature on the polymer yields could be observed. This result is quite different from the polymerization of MAN.

The ratios of the AN monomer units to one PEO chain in the copolymer (AN/PEO) were obtained from ${ }^{1} \mathrm{H}$ NMR spectra, and are listed in Table II. The values of AN/PEO of copolymers are considerably greater than that expected from the values of $\mathrm{M} / \mathrm{I}$. Thus, the efficiency of the initiator is considered to be low. It may be reasonable to consider from this result that the amount of triblock copolymer is small. As discussed below, the amount of PAN homopolymer is not always negligible.

\section{The Structure of the PAN Part in the Copolymer}

The ${ }^{1} \mathrm{H}$ NMR spectra of the copolymers prepared at various temperatures are shown in Figure 4. In the spectrum of the copolymer prepared at $30^{\circ} \mathrm{C}$, the methylene proton resonance $(3.5 \delta)$ of PEO, the methine proton resonance $(3.2 \delta)$ and the methylene proton resonance $(2.1 \delta)$ of PAN are observed. ${ }^{15} \mathrm{At}$ $2.8 \delta$, however, a strong absorption not seen in the spectrum of radically prepared PAN is observed. The relative intensity of this absorption decreases with a decrease in the polymerization temperature and finally this absorption is hardly detectable in the spectrum of the copolymer prepared at $-78^{\circ} \mathrm{C}$.

In Figure 5 are shown the ${ }^{13} \mathrm{C}$ NMR spectra of the PAN part in the copolymers prepared at various temperatures. Methine carbon resonance ( $27 \mathrm{ppm})$, methylene carbon resonance (32.6 ppm), and nitrile carbon resonance (120 ppm) of PAN were observed to be the same as that reported previously. ${ }^{16}$ The resonances not appearing in the spectrum of radically prepared PAN were observed at 12.2 and 14.2 ppm in the spectra of the copolymers prepared above $-30^{\circ} \mathrm{C}$. The relative intensities of the unidentified resonances at 12.2 and $14.2 \mathrm{ppm}$ decreased with a decrease in polymerization temperature and these resonances could not be seen in the spectrum of the copolymer prepared at $-78^{\circ} \mathrm{C}$.

These results strongly suggest that a certain kind of side reaction took place during polymerization. The possible reactions involved in this polymeri- 


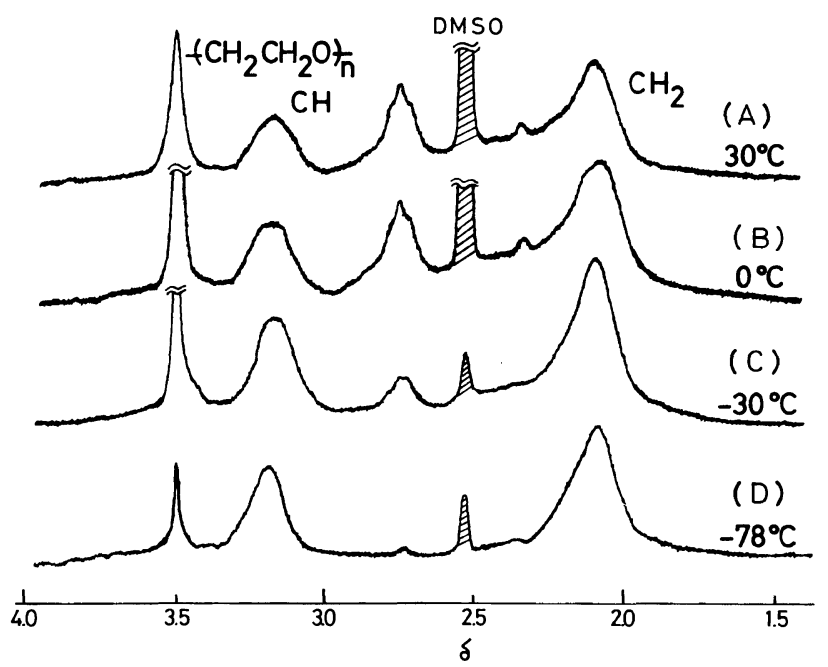

Figure 4. $220 \mathrm{MHz}{ }^{1} \mathrm{H}$ NMR spectra of PEO- $b$-PAN prepared at various temperatures: (A) $30^{\circ} \mathrm{C}$ (No. 10); (B) $0^{\circ} \mathrm{C}$ (No. 13); (C) $-30^{\circ} \mathrm{C}$ (No. 14); (D) $-78^{\circ} \mathrm{C}$ (No. 15).

zation are given as follows ${ }^{12}$ :

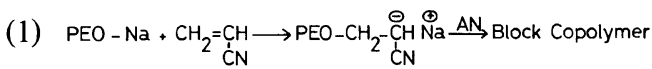

(2) PEO-Na $+\mathrm{CH}_{2}=\underset{\mathrm{CN}}{\mathrm{CH}}$ Metalation,

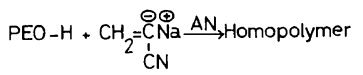

(3)

$$
\begin{aligned}
& \text { PEO }-\mathrm{Na}+\sim \mathrm{CH}_{2}-\underset{\mathrm{CN}}{\mathrm{C}}-\mathrm{CH}_{2}-\underset{\mathrm{CN}}{\mathrm{C}} \sim \stackrel{\text { Metalation, }}{\longrightarrow}
\end{aligned}
$$

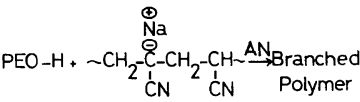

(4)

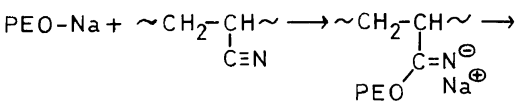

$$
\begin{aligned}
& \sim \mathrm{CH}_{2}-\mathrm{CH}_{1}^{-}+\mathrm{CH}_{2}^{-}{ }_{\mathrm{H}}^{\mathrm{CH}}{ }_{\mathrm{C}}^{\mathrm{CH}} \sim \stackrel{\mathrm{H}^{\oplus}}{\longrightarrow}
\end{aligned}
$$

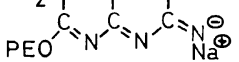

$$
\begin{aligned}
& \sim \mathrm{CH}_{2}-{ }_{\mathrm{C}} \mathrm{CH}_{\mathrm{C}}^{\mathrm{C}} \mathrm{CH}_{2} \mathrm{C}_{\mathrm{C}}^{\mathrm{C}} \mathrm{H} \sim
\end{aligned}
$$

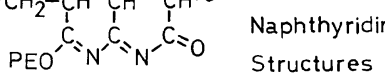

Equation 1: the Michael-type addition of PEO-Na (sodium salt of PEO) to the AN monomer leads to the block copolymer. Equation 2: the metalated ion of AN monomer by PEO-Na leads to the PAN homopolymer. Equation 3: metalation at the me- thine of PAN by PEO-Na occurs and polymerization starts again from there, resulting in a branched PAN. The metalation at the methine of PAN may also occur through a chain transfer from a living chain end. Equation 4: the alkoxy anion of PEO attacks the nitrile carbon of PAN followed by the formation of a naphthyridine-like structures. The anionic polymerization of AN with alkali metal alkoxides or alkyls generally gives a yellow-colored polymer. ${ }^{18-23}$ It has also been reported that pyrolysis, ${ }^{24}$ thermal $^{25-27}$ or alkali ${ }^{28,29}$ treatment of PAN results in coloration. It is widely accepted that this coloration is due to the formation of naphthyridine-like structures. ${ }^{18-20,22,24,28,30}$ The copolymers prepared above $0^{\circ} \mathrm{C}$ were pale-yellow, while those prepared below $-30^{\circ} \mathrm{C}$ were white. To determine whether the unidentified absorptions in the NMR spectra could be ascribed to the naphthyridine-like structures in PAN, an alkali treatment of PAN was carried out. A radically prepared PAN (white solid) was stirred for 18 hours at $30^{\circ} \mathrm{C}$ in a THF solution of the disodium salt of PEO. The reaction mixture was poured into methanol and a methanol-insoluble fraction was recovered as a yellow-colored solid. The ${ }^{1} \mathrm{H}$ and ${ }^{13} \mathrm{C}$ NMR spectra of the alkali-treated PAN were essentially the same as those of radically prepared PAN and the resonances due to the naphthyridine-like structures could not be detected in the ${ }^{13} \mathrm{C}$ NMR spectrum. Consequently, the unidentified reso- 

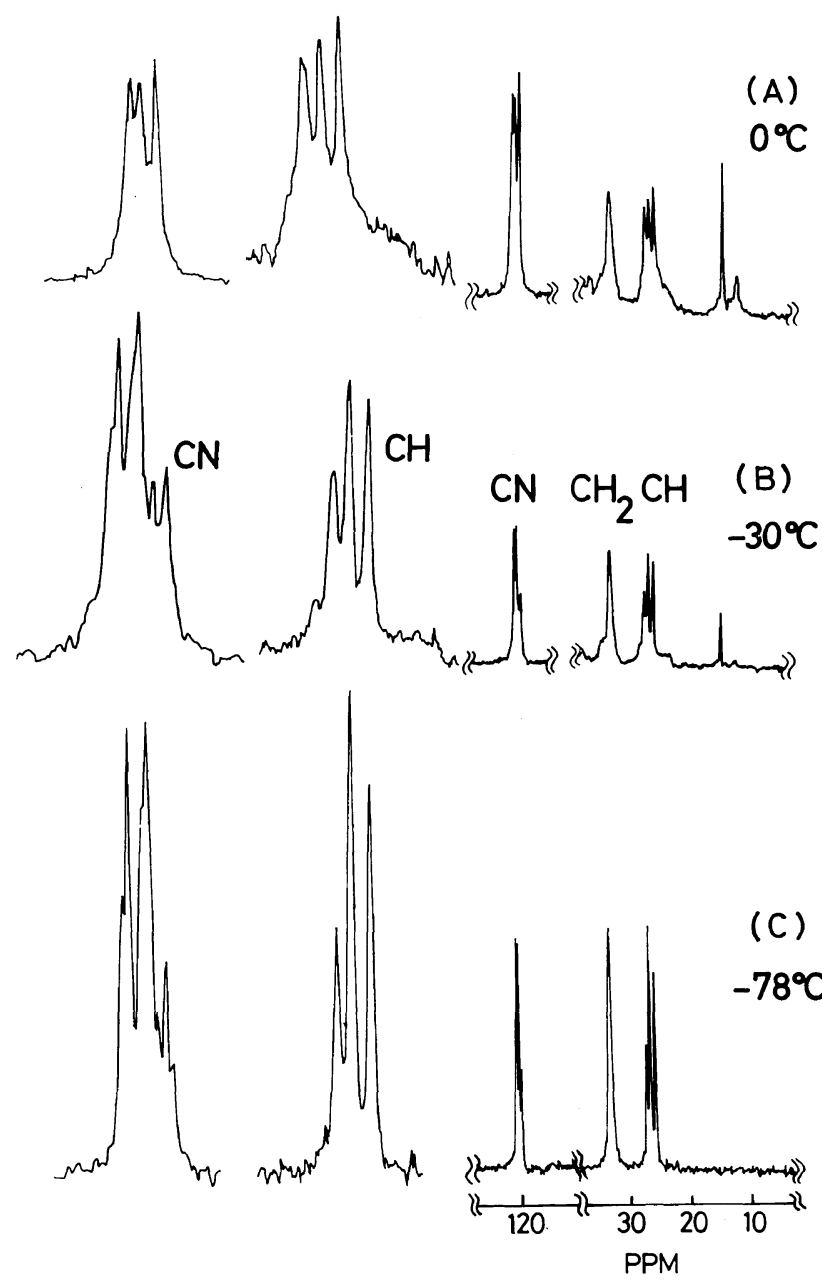

Figure 5. ${ }^{13} \mathrm{C}$ NMR spectra of the PAN part in PEO- $b$-PAN prepared at various temperatures: (A) $0^{\circ} \mathrm{C}$ (No. 13); (B) $-30^{\circ} \mathrm{C}$ (No. 14); (C) $-78^{\circ} \mathrm{C}$ (No. 15).

nances shown in Figures 4 and 5 cannot be ascribed to the naphthyridine-like structures.

The off-resonance decoupled ${ }^{13} \mathrm{C}$ NMR spectrum of the copolymer prepared at $30^{\circ} \mathrm{C}$ was measured. The resonances at 12.2 and $14.2 \mathrm{ppm}$ were observed as singlet and triplet and therefore were assigned as quaternary and methylene carbons, respectively.

If the polymer anion shown in eq 3 is formed, it is possible for it to initiate the polymerization of AN to give the branched PAN shown in Figure 6. In a branching structure, methine carbons are changed into quaternary carbons (carbon-a in Figure 6). The three methylene carbons (carbons-b) adjacent to the quaternary carbon are in a magnetic environment<smiles>CCC(C#N)CC(C#N)(CC(C)C#N)CC(C)CC(C)C#N</smiles>

Figure 6. A model for a branched structure of the PAN part in PEO- $b$-PAN.

different from the other methylene carbons. In the ${ }^{13} \mathrm{C}$ NMR spectra, the absorptions at 12.2 and 14.2 ppm may tentatively be assigned as the carbon-a and the carbons-b, respectively. The resonance at 
$2.8 \delta$ in the ${ }^{1} \mathrm{H}$ NMR spectra can be assigned to the methylene protons in the branched PAN (protons bonded to carbons-b).

It is reported that the metalation reaction of monomer is likely to occur in the anionic polymerization of AN with $n$-butyllithium. ${ }^{17}$ However, similar branching was observed in the anionic polymerization of $t$-butyl-2,4-pentadienoate initiated with $t$-butyllithium. ${ }^{31}$ In the polymerization of MAN as described above, such unidentified resonances in the ${ }^{1} \mathrm{H}$ and ${ }^{13} \mathrm{C}$ NMR spectra were not observed, as may be expected from the absence of $\alpha$ hydrogen. These results strongly support the formation of a branched structure in the PAN part of the copolymer by the metalation reaction of PAN.

The relative intensities of the unidentified peaks in the NMR spectra decreased with a decrease in the polymerization temperature and they were undetectable in the spectra of the copolymer prepared at $-78^{\circ} \mathrm{C}$. It is obvious, therefore, that the amount of branched structure in PAN decreases with a decrease in the polymerization temperature and is negligible in the copolymer prepared at $-78^{\circ} \mathrm{C}$.

\section{REFERENCES}

1. A. Noshay and J. E. McGrath, "Block Copolymers," Academic Press, New York, 1977.

2. T. Suzuki, Y. Murakami, Y. Tsuji, and Y. Takegami, J. Polym. Sci., Polym. Lett. Ed., 14, 675 (1976).

3. T. Suzuki, Y. Murakami, and Y. Takegami, $J$. Polym. Sci., Polym. Lett. Ed., 17, 241 (1979).

4. T. Suzuki, Y. Murakami, and Y. Takegami, Polym. J., 12, 183 (1980).

5. T. Suzuki, O. Yamada, Y. Murakami, Y. Takegami, and Y. Watanabe, Macromolecules, in press.

6. A. Zilkha, B. A. Feit, and M. Frankel, J. Chem. Soc., 928 (1959).

7. A. Zilkha and B. A. Feit, J. Appl. Polym. Sci., 5, 251 (1961).
8. B. A. Feit, J. Wallach, and A. Zilkha, J. Polym. Sci., A, 2, 4743 (1964).

9. I. M. Panayotov, C. B. Tsvetanov, and D. K. Dimov, Markomol. Chem., 177, 279 (1976).

10. S. Yanagida, K. Takahashi, and M. Okahara, Bull. Chem. Soc. Jpn., 50, 1386 (1977).

11. J. Furukawa, T. Saegusa, and N. Mise, Makromol. Chem., 38, 244 (1960).

12. J. C. Galin, Makromol. Chem., 124, 118 (1969).

13. T. Suzuki, S. Koshiro, and Y. Takegami, Polymer, 14, 549 (1973).

14. Y. Inoue, K. Koyama, R. Chûjô, and A. Nishioka, $J$. Polym. Sci., Polym. Lett. Ed., 11, 55 (1973).

15. R. Yamadera and M. Murano, J. Polym. Sci., A-1, 5, 1059 (1967).

16. Y. Inoue and A. Nishioka, Polym. J., 3, 149 (1972).

17. N. Kawabata and T. Tsuruta, Makromol. Chem., 98, 262 (1966).

18. C. G. Overberger, E. M. Pearce, and N. Mayes, $J$. Polym. Sci., 31, 217 (1958).

19. C. G. Overberger, E. M. Pearce, and N. Mayes, $J$. Polym. Sci., 34, 109 (1959).

20. C. G. Overberger, H. Yuki, and N. Urakawa, J. Polym. Sci., 45, 127 (1960).

21. A. Zilkha, B. A. Feit, and M. Frankel, J. Polym. Sci., 49, 231 (1961).

22. R. B. Cundall, D. D. Eley, and J. Worrall, J. Polym. Sci., 58, 869 (1962).

23. A. Ottolenghi and A. Zilkha, J. Polym. Sci., A-1, 687 (1963).

24. W. J. Burlant and J. L. Parsons, J. Polym. Sci., 22, 249 (1956).

25. N. Grassie and J. N. Hay, J. Polym. Sci., 56, 189 (1962).

26. N. Grassie and R. McGuchan, Eur. Polym. J., 8, 257 (1972).

27. L. Patron, C. Mazzolini, and A. Moretti, J. Polym. Sci., C, No. 42, 405 (1973).

28. T. Takata, I. Hiroi, and M. Taniyama, J. Polym. Sci., $A-2,1567$ (1964).

29. N. S. Batty and J. T. Guthrie, Polymer, 19, 1145 (1978).

30. T. Shimomura, E. Tsuchida, and I. Shinohara, Kogyo Kagaku Zasshi, 70, 975 (1967).

31. T. Suzuki, O. Yamada, Y. Tsuji, Y. Watanabe, and Y. Takegami, Polym. Prepr., Jpn., 28(5), 926 (1979). 